\title{
Effect of Polypropylene Fibres on Flexural Strength of M30 Grade Concrete
}

\author{
${ }^{1}$ Mohit Dwivedi, ${ }^{2}$ Shobhit Mishra, ${ }^{3}$ Vishal Singh \\ ${ }^{1,2,3}$ VIT University
}

\begin{abstract}
Concrete made with Portland cement has strong compressive strength but it has weak tensile strength and it tends to be brittle. Also cracks start to develop as soon as concrete is placed and before it has properly hardened which may lead to weakening of concrete structures, fracture and failure and general lack of durability.

Thus this research is aimed at reducing the aforementioned shortcomings of concrete to increase its applicability and performance. The tensile strength of concrete could be enhanced by using conventional rod reinforcements and to a certain extent by the inclusion of a sufficient volume of fiber. Addition of fibers also leads to a reduction in shrinkage cracking. We have used steel fibers as reinforcements and Polypropylene as the fiber.
\end{abstract}

Keywords: Concrete, Fiber Reinforced Concrete, M30 grade concrete, Polypropylene, PP fiber.

\section{○ Polypropylene Fibers}

\section{Introduction}

Polypropylene (PP) is a versatile and widely used polymer. Polypropylene resins are a general class of thermoplastics produced from propylene gas. Propylene gas is derived from the cracking of natural gas feedstock's or petroleum by-products. Under broad ranges of pressures and temperatures, propylene generally polymerizes to form very long polymer chains. However, to make polypropylene resins with controlled configurations of molecules (tactility) at reasonably acceptable commercial rates, special catalysts are required.

Polypropylene fibers belong to the newest generation of large-scale, manufactured chemical fibers, having the fourth largest volume in production after polyesters, polyamides and acrylics [1, 2]. PP is one of the most successful commodity fibers, reaching a world production capacity of four million tons a year. Due to its low density $(0.9 \mathrm{gm} . / \mathrm{cc})$, high crystalline, high stiffness and excellent chemical/bacterial resistance, is tactic PP is widely used in many industrial applications such as nonwovens, industrial ropes, packaging materials, furnishing products, etc. PP fiber has potential, high-volume applications in the carpet, textile, apparel and industrial textile markets.

- Advantages of using PP fibers

The following are the advantages of using polypropylene fibers-

- $\quad$ easy processing

- low specific gravity

- almost zero water adsorption

- good chemical resistance

- Wide availability and Low cost.

- Objective

To find out the enhancement in flexural strength of M30 Grade cylindrical concrete block having the dimensions- 500 X $100 \times 100 \mathrm{~mm}$; on addition of polypropylene plastic in the mix.

○ Materials used

The following materials were used-

- Blast furnace slag

- Cement

- Polypropylene Plastic

- $\quad$ Fine aggregates

- Coarse aggregates

- Water 
- Blast furnace slag properties

Blast furnace slag is obtained by quenching molten iron slag (a by-product of iron and steel-making) from a blast furnace in water or steam, to produce a glassy, granular product that is then dried and ground into a fine powder.

- Coarse Aggregates properties

$\square$ Coarse aggregates were used with $20 \mathrm{~mm} \& 12 \mathrm{~mm}$ nominal size.

$12 \mathrm{~mm}$ aggregates was used $40 \%$ in coarse aggregates.

$20 \mathrm{~mm}$ aggregates was $\mathrm{eed} 60 \%$ in coarse aggregates.

The specific gravity of coarse aggregates is 2.7 .

- Fine Aggregates properties

$\square \square$ Fine modulus of fine aggregate 4.013

- Cement Properties

$\checkmark$ Ordinary Portland cement 53 grade conforming to IS: 122691987 was used.

The specific gravity of cement is 3.2 .

- Mix Proportion

Water: Cement: Fine aggregate: Coarse aggregate - 0.42:1:1:2

\section{Literature Reviews}

Martínez-Barrera, Fernando Ureña-Nuñez,OsmanGencel, WitoldBrostow Gonzalo, in“Mechanical properties of polypropylene-fiber reinforced concrete after gamma irradiation" have showed that the compressive strength and the elastic modulus are the highest for concrete with $1.5 \mathrm{vol} \%$ of PP fibers. Improvement of the strength and elastic modulus was dependent on PP fiber concentration, marble particle sizes and the applied dose. "Martínez-Barrera G, Martínez-Hernández AL, Velasco-Santos C, Brostow W.2009 Polymer concretes improved by fiber reinforcement and gamma irradiation. E-Polym, 103:1-10."

N.Angelidis, C.Y.Wei, investigate the effect of mechanical strain on potential distributions and resistance of unidirectional and multidirectional carbon fiber epoxy laminates. The effects of current flow direction and technique for current introduction on piezoresistance have been studied. It was found that uniform current introduction at sample edges produced by sputtered $\mathrm{Au}-\mathrm{Cr}$ contacts across the entire cross-section produced consistently low values of gauge factor of 1.75 for current flow parallel to the fibers and 2.7 for transverse current flow. Non-uniform current introduction, produced variously by local point introduction of current, or use of viscous adhesives producing intermittent contact, resulted in a wide range of apparent gauge factors ranging from 20.6 to 28.9. These anomalous values may be explained by a model in which the high anisotropy of resistance in unidirectional CFRP maintains initial non-uniform current throughout the sample. Under mechanical strain points of fiber contact will change, altering the distribution of current carrying fibers and leading to local changes in current. Thus changes in potential difference between two points produced by mechanical strain will not be exclusively caused by changes in local resistance. The presence of transverse plies in multidirectional laminates ensures that in plane non-uniform current distributions are largely eliminated, and the effect on piezo-resistance of non-uniform current introduction is minimized. "The electrical resistance response of continuous carbon fibre composite laminates to mechanical strain, N. Angelidis, C.Y. Wei and P.E. Irving, Composites Part A: Applied Science and Manufacturing, Volume 37, Issue 9, September 2006, Pages 1490-1494"

K.Murahari, Rama Mohan Rao P. showed that the increase of mechanical properties (compressive and flexural strength) resulting from added of polypropylene fiber was relatively high. "Effects of Polypropylene fibers on the strength properties of fly ash based concreteK.Murahari, Rama mohanRaoP,International Journal of Engineering Science Invention ISSN (Print): 2319 - 6726 www.ijesi.org Volume 2 Issue 5 May. 2013 PP.1319 "

\section{○ Preliminary Tests}

\section{Methodology}

Fineness Modulus of Fine Aggregate

About $1000 \mathrm{gm}$. fine aggregate was weighed. The sieves were cleaned with brush and the sieves were then arranged one over the other in the order of their mesh openings, $4.75 \mathrm{~mm}$ sieve being at the top and 0.075 $\mathrm{mm}$ sieve being at the bottom. Then the sieves were shaken in the mechanical sieve shaker for about 10 minutes and the readings were taken. 
Fineness Modulus Of Course Aggregate

About 200 gm. dried coarse aggregate was weighed.The sieves were cleaned with brush and the sieves were then arranged one over the other in the order of their mesh openings, $80 \mathrm{~mm}$ sieve being at the top and 10 $\mathrm{mm}$ sieve being at the bottom. Then the sieves were shaken in the mechanical sieve shaker for about 10 minutes and the readings were taken.

\section{$\circ$ Casting}

The materials were weighed based on calculations obtained for the mix proportion 0.42:1:1:2.Cement, fine aggregate, coarse aggregate and reinforcement steel were taken and mixed for the lower half of the concrete slab.The interior surface of the mold was cleaned, grease was applied and then prepared mix was placed in the mold in layers and each layer was compacted.

Then cement, fine aggregate, coarse aggregate, slag and polypropylene plastic were taken and mixed for the upper half of the concrete slab.The prepared mix was placed in the mold in layers and each layer was compacted.Then the prepared concrete slab along with the mold was kept on the vibrating table for compacting. After that the assembly was kept to dry for 24 hours.After 24 hours the mold was opened and the concrete block was ponded for curing. The flexural strength readings were taken on day 7 and day 28 .

\section{Results Of Experiments}

○ Preliminary Tests

Fineness Modulus Of Fine Aggregate

\begin{tabular}{|l|l|l|l|l|}
\hline Serial No. & \multicolumn{1}{|c|}{ Sieve Size } & $\begin{array}{c}\text { Weight retained } \\
\text { (gm.) }\end{array}$ & \% weight retained & $\begin{array}{c}\text { Cumulative \% weight } \\
\text { retained }\end{array}$ \\
\hline 1 & $4.75 \mathrm{~mm}$ & 43 & 4.3 & 4.3 \\
\hline 2 & $2.36 \mathrm{~mm}$ & 66 & 6.6 & 10.9 \\
\hline 3 & $1.18 \mathrm{~mm}$ & 810 & 81 & 91.9 \\
\hline 4 & 600 micron & 40 & 4.0 & 95.9 \\
\hline 5 & 300 micron & 25 & 2.5 & 98.4 \\
\hline 6 & 150 micron & 15 & 1.5 & 99.9 \\
\hline 7 & 75 micron & & & 100 \\
\hline 8 & Pan & 1 & 0.1 & \\
\hline
\end{tabular}

Table-1 Fineness modulus of fine aggregate

Fineness modulus

$=$ cumulative $\%$ retained $/ 100$

$=4.013$

Fineness Modulus Of Coarse Aggregate

\begin{tabular}{|c|c|c|c|c|}
\hline Serial No. & Sieve Size & $\begin{array}{c}\text { Weight retained } \\
\text { (gm.) }\end{array}$ & $\%$ weight retained & $\begin{array}{c}\text { Cumulative \% weight } \\
\text { retained }\end{array}$ \\
\hline 1 & $20 \mathrm{~mm}$ & 1390 & 27.85 & 27.85 \\
\hline 2 & $12.5 \mathrm{~mm}$ & 2711 & 54.32 & 82.17 \\
\hline 3 & $10 \mathrm{~mm}$ & 704 & 14.11 & 96.28 \\
\hline 4 & $4.75 \mathrm{~mm}$ & 186 & 3.72 & 100 \\
\hline 5 & $2.36 \mathrm{~mm}$ & 0 & 0 & 100 \\
\hline 6 & $1.18 \mathrm{~mm}$ & 0 & 0 & 100 \\
\hline 7 & 600 micron & 0 & 0 & 100 \\
\hline 8 & 300 micron & 0 & 0 & 100 \\
\hline 9 & 150 micron & 0 & 0 & 100 \\
\hline 10 & Pan & 0 & 0 & 100 \\
\hline
\end{tabular}

Table-2 Fineness modulus of coarse aggregate

Fineness modulus

$=$ cumulative $\%$ retained $/ 100$

$=7.063$ 
○ Flexural Strength Test Results

\begin{tabular}{|c|c|c|c|}
\hline SLAG DOSAGE \% & STEEL AND PP \% & $7^{\text {th }}$ day strength & $28^{\text {th }}$ day strength \\
\hline \multirow{4}{*}{$10 \%$} & $0 \%$ & 2.50 & 3.85 \\
\hline & $0.1 \%$ & 5.58 & 8.45 \\
\hline & $0.2 \%$ & 6.05 & 8.65 \\
\hline & $0.3 \%$ & 6.28 & 8.84 \\
\hline \multirow[t]{4}{*}{$20 \%$} & $0 \%$ & 2.42 & 3.86 \\
\hline & $0.1 \%$ & 5.54 & 8.33 \\
\hline & $0.2 \%$ & 6.00 & 8.62 \\
\hline & $0.3 \%$ & 6.19 & 8.79 \\
\hline \multirow[t]{4}{*}{$30 \%$} & $0 \%$ & 2.36 & 3.86 \\
\hline & $0.1 \%$ & 5.49 & 8.44 \\
\hline & $0.2 \%$ & 5.95 & 8.68 \\
\hline & $0.3 \%$ & 6.12 & 8.77 \\
\hline \multirow[t]{4}{*}{$40 \%$} & $0 \%$ & 2.32 & 3.88 \\
\hline & $0.1 \%$ & 5.47 & 8.48 \\
\hline & $0.2 \%$ & 5.88 & 8.69 \\
\hline & $0.3 \%$ & 6.08 & 8.82 \\
\hline \multirow[t]{4}{*}{$50 \%$} & $0 \%$ & 2.29 & 3.89 \\
\hline & $0.1 \%$ & 5.44 & 8.52 \\
\hline & $0.2 \%$ & 5.77 & 8.71 \\
\hline & $0.3 \%$ & 6.03 & 8.91 \\
\hline
\end{tabular}

Table-3 Flexural Strength values

\section{Figures}

Figure 1: $28^{\text {th }}$ day Flexural Strength v/s Steel and PP \%

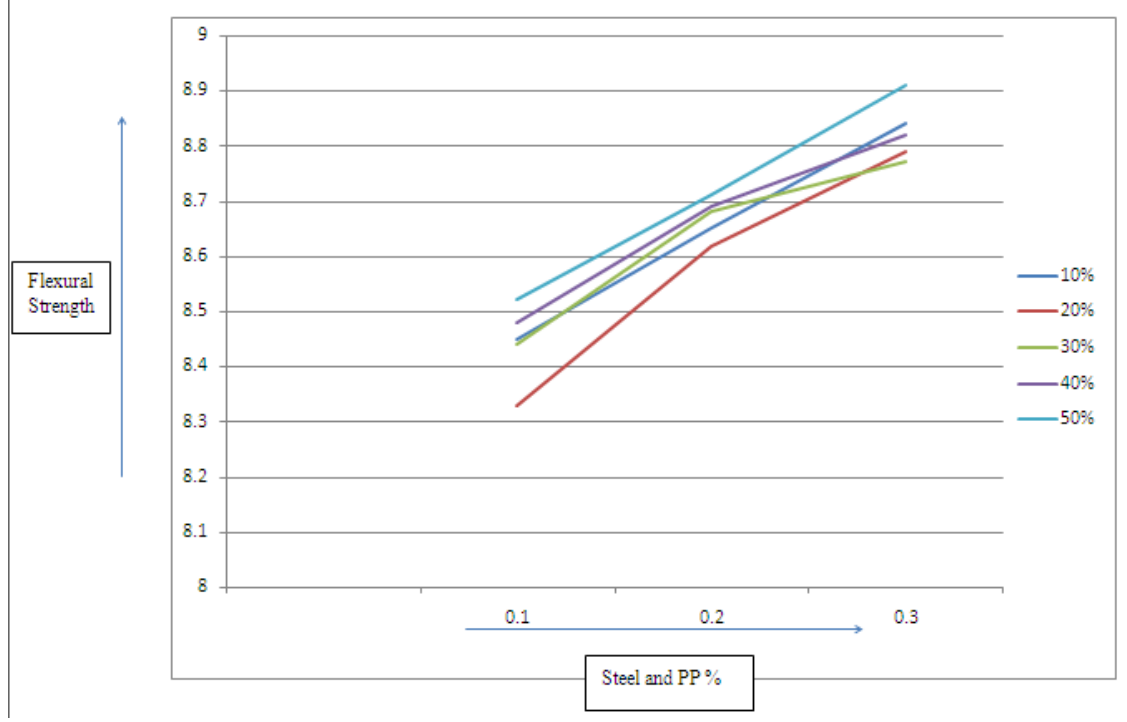

Figure 1 depicts the variation of flexural strength of specimen for $10-50 \%$ slag dosage, with increasing amount of Steel and PP content.

Almost straight lines, with positive slopes obtained in figure 1 indicate that for a constant amount of slag dosage, with the increase in amount of steel reinforcement and plastic fiber, an increase in flexural strength of concrete slab is observed.

\section{Conclusions}

Various conclusions could be drawn from this experimental study-

- The increase in flexural strength from day 7 to day 28 , for the same specimen was found to be in the range of $65-75 \%$.

○ On increasing the dosage of slag by $10 \%$, the flexural strength was found to increase by $0.3-0.5 \%$.

- The flexural test of concrete gradually increases with the addition of Polypropylene fiber.

- Almost straight lines, with positive slopes obtained in figure-1 indicate that for a constant amount of slag dosage, with the increase in amount of steel reinforcement and plastic fiber, an increase in flexural strength of concrete slab is observed. 
- For a fixed amount of slag content, on increasing the volume \% of slag and PP fibers, flexural strength increases in the range of $2-2.5 \%$.

\section{Refernces}

[1]. Martínez-Barrera G, Martínez-Hernández AL, Velasco-Santos C, Brostow W.2009 Polymer concretes improved by fiber reinforcement and gamma irradiation. E-Polym, 103:1-10.

[2]. The electrical resistance response of continuous carbon fibre composite laminates to mechanical strain, N. Angelidis, C.Y. Wei and P.E. Irving, Composites Part A: Applied Science and Manufacturing, Volume 37, Issue 9, September 2006, Pages 1490-1494

[3]. Effects of Polypropylene fibers on the strength properties of fly ash based concreteK.Murahari, Rama mohanRaoP, International Journal of Engineering Science Invention ISSN (Print): 2319 - 6726 www.ijesi.org Volume 2 Issue 5 May. 2013 PP.13-19 